\title{
Food intake regulating hormones in adult craniopharyngioma patients
}

\author{
J Roemmler-Zehrer ${ }^{1,+}$, V Geigenberger ${ }^{1}$, S Störmann ${ }^{1}$, M Losa ${ }^{3}$, V Crippa ${ }^{3}$, B Otto ${ }^{1}$, \\ M Bidlingmaier ${ }^{1}$, C Dimopoulou ${ }^{1,2}$, G K Stalla ${ }^{2}$ and J SchopohI ${ }^{1}$ \\ ${ }^{1}$ Medizinische Klinik und Poliklinik IV, Klinikum der Universität München, Ziemssenstraße 1, 80336 München, \\ Germany, ${ }^{2}$ Max-Planck-Institute of Psychiatry, Munich, Germany and ${ }^{3}$ Department of Neurosurgery, \\ Istituto Scientifico San Raffaele, Università Vita-Salute, Milan, Italy \\ ${ }^{\dagger}$ (J Roemmler-Zehrer is now at Joseph-Wild-Str. 20, 81829 München, Germany)
}

\section{Abstract}

Introduction: Patients with craniopharyngioma (CP) have disturbances of the hypothalamic-pituitary axis and serious comorbidities such as obesity. We hypothesized that the secretion of hormones regulating the nutritional status is altered in adult patients with CP compared with patients with non-functioning pituitary adenoma (NFPA).

Methods: We included 40 CP (50\% males, mean age: $49.6 \pm 14.3$ years) and 40 NFPA ( $72.5 \%$ males, mean age: $63.4 \pm 9.8$ years) patients. We measured glucose, insulin, leptin, total ghrelin, peptide-YY (PYY) and cholecystokinin (CCK) during oral glucose tolerance test (OGTT). Fat mass (FM) was determined by dual X-ray absorptiometry.

Results: Gender distribution was not significantly different, but CP patients were significantly younger $(P<0.001)$. CP patients had significantly higher BMI and FM than NFPA patients (BMI $32 \pm 8$ vs $28 \pm 4 \mathrm{~kg} / \mathrm{m}^{2}, P=0.009$ and FM $37 \pm 9$ vs $33 \pm 9 \%$, $P=0.02)$. Fasting glucose level ( $84 \pm 12 \mathrm{vs} 78 \pm 11 \mathrm{mg} / \mathrm{dl}, P=0.03)$, leptin $(27.9 \pm 34.2 \mathrm{vs} 11.9 \pm 11.6 \mu \mathrm{g} / \mathrm{l}, P=0.008)$ and leptin levels corrected for percentage FM $(0.66 \pm 0.67$ vs $0.32 \pm 0.25 \mu \mathrm{g} / \mathrm{l} \%, P=0.005)$ were significantly higher in CP than in NFPA patients, whereas ghrelin was significantly lower (131 \pm 129 vs $191 \pm 119 \mathrm{ng} / \mathrm{l}, P=0.035)$. Insulin, PYY and CCK did not differ significantly between groups. After glucose load, leptin decreased significantly in CP patients $(P=0.019)$. In both groups, ghrelin decreased significantly during OGTT (both $P<0.001$ ). The percentage decline was significantly smaller for CP. PYY and CCK increased equally after glucose in both groups.

Conclusion: Our patients with CP have more metabolic complications than our patients with NFPA. The levels of leptin and ghrelin at fasting status and after glucose seem to be altered in CP, whereas changes in insulin, PYY and CCK do not seem to be responsible for the metabolic changes in these patients.

\section{Introduction}

Patients with craniopharyngioma (CP) often suffer from obesity and features of the metabolic syndrome. One reason seems to be the location of the tumor which lies in the pituitary-hypothalamic region. Especially, suprasellar growth and damage of the medial ventral part of the hypothalamus leads to disturbances in food regulation and weight gain $(1,2)$. Significant weight gain is on the one hand caused by the tumor location itself (3), on the other hand by consecutive treatment, surgery and radiation of the tumor (4). This kind of obesity is called
European Journal of Endocrinology (2014) 170, 627-635 hypothalamic obesity and is defined by a rapid, unyielding weight gain, which is almost untreatable (5).

By now, several circulating peptides such as insulin, leptin, ghrelin, peptide-YY (PYY), glucagon-like peptide 1 and cholecystokinin (CCK) are known to influence weight regulation by affecting the hypothalamic nuclei $(6,7)$. It is assumed that in patients with $\mathrm{CP}$, the central response to these peptides is disturbed due to hypothalamic damage leading to obesity $(5,8)$. Hyperinsulinemia, which is thought to be one reason for obesity in humans, might be 
due to increased vagal tone caused by lesions in the ventromedial nuclei (9). Leptin is produced in fat cells and correlates positively with the amount of fat mass (FM) (10). Leptin resistance of the hypothalamus and high circulating leptin levels have been shown in general obesity and in patients with $\mathrm{CP}$, who have a greater leptin resistance compared with obese controls (11). Ghrelin is a hunger hormone and is produced in the endocrine X/A-like cells of the gastric mucosa (12). Ghrelin levels are high during fasting and in lean subjects and low after food intake and in obesity (13). Patients with CP seem to have neither changes in ghrelin levels compared with obese controls (14) nor hypoghrelinemia and reduced post-meal response compared with patients with general obesity (15). PYY is a strong appetite-restricting gut peptide, which is secreted by the L cells of the lower intestine (16). PYY-knockout mice suffer from hyperphagia and obesity and exogenous replacement of PYY can stop uncontrolled food intake (17). In obese and normal-weight CP patients, the increase in PYY after a meal was weaker compared with obese and normal-weight controls respectively (15). Neither have significant differences in secretion pattern reported when comparing obese $\mathrm{CP}$ patients with obese controls (18). Also in adult patients with tumors in the hypothalamic region - mostly patients with CP - PYY secretion was not changed after a mixed meal compared with healthy controls (19). CCK is produced in the intestinal tract (20); it is secreted after food intake and also restrains appetite.

We performed this cross-sectional study in a large cohort of patients with CP to get more information about the pattern of the appetite-regulating hormones such as insulin, leptin, ghrelin, PYY and CCK in these patients. Patients with non-functioning pituitary adenoma (NFPA) were used as a control group, because they also have a central lesion lying in the pituitary-hypothalamic region.

As patients with CP have greater damage of the pituitary-hypothalamic area than patients with NFPA, we hypothesized that they should have more disturbances in hormones influencing the nutritional status as well as more signs of the metabolic syndrome.

\section{Subjects and methods}

\section{Subjects}

We informed all patients with $\mathrm{CP}$, treated at the Medizinische Klinik und Poliklinik IV of the Ludwig-Maximilians-Universität (LMU) Muenchen, and the Max-Planck-Institute (MPI) of Psychiatry, both
Munich, Germany, and the Department of Neurosurgery, Istituto Scientifico San Raffaele, Università Vita-Salute, Milano, Italy, about this cross-sectional study. A total of 33 patients from Germany and seven patients from Italy agreed to participate. Nine patients had childhood onset and 31 patients had adult onset of CP. Mean age at diagnosis was $35 \pm 19$ years. In addition, 40 patients with non-functioning pituitary macroadenomas of the LMU and the MPI were asked to take part in the study as a control group. The study protocol was reviewed and approved by the Ethics Committee of the Medical Faculty of the LMU Muenchen. All patients gave informed consent to participate. Patients with diabetes mellitus (DM) currently on or requiring insulin therapy were excluded from the study. All patients with corticotropic insufficiencies and thyreotropic axis as well as patients with diabetes insipidus were on permanent, sufficient substitution (hydrocortisone 15-25 mg/day, thyroxine $\left(\mathrm{T}_{4}\right)$ titrated by free $\mathrm{T}_{4}$ level, desmopressin controlled by serum electrolytes and clinical symptoms). Male patients with insufficiency of the gonadotropic axis received adequate testosterone substitution and female patients with insufficiency of the gonadotropic axis sex steroids until reaching postmenopausal age. Growth hormone $(\mathrm{GH})$ substitution was offered to all GH-deficient patients who did not have contraindications for substitution (Table 1).

\section{Methods}

All evaluations of the German patients were performed in the Medizinische Klinik und Poliklinik IV, of the Italian patients in the Istituto Scientifico San Raffaele, Università Vita-Salute according to the same protocol. The patients were asked to arrive at the hospital between 0700 and $0900 \mathrm{~h}$ after overnight fasting. We first determined clinical parameters and body composition and then baseline laboratory values. Afterwards, we performed a 3-h oral glucose tolerance test (OGTT, time points $-15,0,30,60$, 90, 120, 150 and $180 \mathrm{~min}$ ) with $75 \mathrm{~g}$ glucose (Dextro O.G-T., Roche) according to the World Health Organization (WHO) criteria and measured glucose and insulin at all time points in all patients $(n=80)$, serum leptin and serum total ghrelin at time point $-15 \mathrm{~min}$, baseline, and at 60 min in all patients $(n=80)$, and PYY and CCK at time point $-15 \mathrm{~min}$, baseline, and at $60 \mathrm{~min}$ in 23 German patients with CP and 32 German patients with NFPA. Leptin, ghrelin, PYY and CCK was measured only 60 min after glucose load at this time point has been shown to be the most important during OGTT $(15,21,22)$. Blood samples were immediately chilled and centrifuged at $4{ }^{\circ} \mathrm{C}$ 
Table 1 Characteristics and variables of patients with CP and NFPA. Data are shown in mean \pm s.D. Comparisons were calculated using Fisher's exact test and independent two samples $t$-test.

\begin{tabular}{|c|c|c|c|}
\hline & $\mathbf{C P}$ & NFPA & $P$ value \\
\hline Patients $(n)$ & 40 & 40 & \\
\hline Age (years) & $49.3 \pm 14.3$ & $63.4 \pm 9.8$ & $<0.001$ \\
\hline Gender $(f(\%) / m)$ & $20(50) / 20$ & $11(27.5) / 29$ & 0.066 \\
\hline \multicolumn{4}{|l|}{ Pituitary insufficiencies } \\
\hline Corticotrope $(n / \%)$ & $34 / 85$ & $30 / 75$ & NS \\
\hline Thyreotrope $(n / \%)$ & $34 / 85$ & $29 / 73$ & NS \\
\hline Gonadotrope $(n / \%)$ & $36 / 90$ & $31 / 78$ & NS \\
\hline Somatotrope $(n / \%)$ & $36 / 90$ & $28 / 70$ & $<0.05$ \\
\hline Diabetes insipidus $(n / \%)$ & $24 / 60$ & $5 / 13$ & $<0.001$ \\
\hline GH substitution ( $n / \%)$ & $21 / 52.5$ & $12 / 30$ & NS \\
\hline Number of operations $=1$ & $25 / 62.5 \%$ & $25 / 62.5 \%$ & NS \\
\hline Number of operations $>1$ & $15 / 37.5 \%$ & $14 / 35 \%$ & NS \\
\hline Pituitary radiation $(n / \%)$ & $9 / 22.5 \%$ & $18 / 45 \%$ & NS \\
\hline BMI $\left(\mathrm{kg} / \mathrm{m}^{2}\right)$ & $32 \pm 8$ & $28 \pm 4$ & $<0.05$ \\
\hline Fat mass $(\%)$ & $37 \pm 9$ & $33 \pm 9$ & $<0.05$ \\
\hline Waist:hip ratio & $0.94 \pm 0.08$ & $0.96 \pm 0.07$ & NS \\
\hline Glucose $(\mathrm{mg} / \mathrm{dl})$, baseline & $84 \pm 12$ & $78 \pm 11$ & $<0.05$ \\
\hline Glucose $(\mathrm{mg} / \mathrm{dl}), 120 \mathrm{~min}$ & $127 \pm 51$ & $117 \pm 42$ & NS \\
\hline HbA1c $(\%)$ & $5.9 \pm 0.9$ & $5.7 \pm 0.4$ & NS \\
\hline IGF1 $(\mu \mathrm{g} / \mathrm{l})$ & $130 \pm 95$ & $102 \pm 58$ & NS \\
\hline Hypertension (n/\%) & $16 / 40 \%$ & $28 / 70 \%$ & $<0.05$ \\
\hline DM2 $(n / \%)$ & $7 / 18 \%$ & $4 / 10 \%$ & NS \\
\hline $\begin{array}{l}\text { DM2 on oral } \\
\text { antidiabetics }(n / \%)\end{array}$ & $7 / 18 \%$ & $2 / 5 \%$ & NS \\
\hline
\end{tabular}

$n$, number of patients; $f$, female; $m$, male; IGF1, insulin-like growth factor 1 ; DM, diabetes mellitus; NS, not significant.

and serum aliquots were frozen until assayed. Blood samples for leptin and ghrelin from Italy were sent to Munich deep frozen to be measured by the same assay.

\section{Evaluation of clinical parameters}

Weight of patients was measured by using bioelectric impedance analysis scale (Tanita, Firma Soehnle, Model Volga TR51025, Nassau, Germany) wearing only underwear and without shoes; height, waist and hip circumference were measured by tape; heart rate by palpation of pulse and blood pressure by a commonly used blood pressure cuff. For evaluation of total body FM, body composition was determined by dual energy X-ray absorptiometry (Lunar Prodigy, General Electric (Nuernberg, Germany), software version Encore 9.30).

\section{Laboratory values}

Glucose levels were determined by an automated glucose analyzer (Care Eco solo I, Care Diagnostic, Voerde (Niederrhein), Nordrhein-Westfalen, Germany); insulin levels were measured by the Adaltis Italia insulin RIA (S.p.A; Casalecchio di Reno, Italy). HbA1c levels were analyzed from the whole blood, standardized to IFCC and calculated according to DCCT/NGSP (Integra 700, Roche). Insulin-like growth factor 1 (IGF1) concentrations were measured using an automated chemiluminescent immunoassay (Immulite, Diagnostic Products Corporation, Los Angeles, CA, USA).

Leptin concentration in serum was measured using an immunofluorometric in-house assay (IFMA) as described previously (23). The lower limit of quantification was $0.1 \mu \mathrm{g} / \mathrm{l}$ and the linear working range was $0.2-40 \mu \mathrm{g} / \mathrm{l}$. Samples measured above this range have been re-assayed after dilution in 0-standard. Intra-assay variability was $7.4,4.3$ and $5.6 \%$ at leptin concentrations of 0.8 , 2.5 and $15.3 \mu \mathrm{g} / \mathrm{l}$ respectively. Inter-assay variability at the same concentrations was 8.3, 5.2 and 5.9\% respectively. Spiking experiments revealed that this IFMA for leptin measures total leptin independently from the formation of leptin/leptin receptor complexes.

Immunoreactive total human serum ghrelin was measured by a commercially available RIA (Phoenix Pharmaceuticals, Mountain View, CA, USA). Serum ghrelin was measured by using ${ }^{125}$ I-labeled bioactive ghrelin as a tracer and a polyclonal antibody raised in rabbits against the C-terminal end of human ghrelin. All samples from individual subjects were measured by the same assay. Intra- and inter-assay coefficients of variation (CV) were 5.3 and $13.6 \%$ respectively.

Immunoreactive total human plasma PYY was measured by a commercially available RIA (LINCO Research, MO, USA) using ${ }^{125}$ I-labeled bioactive PYY as a tracer and a PYY antiserum to determine the level of active PYY by the double-antibody technique. The PYY antibody is raised in guinea pigs and recognizes both the PYY 1-36 and PYY 3-36 forms of human PYY. All samples from individual subjects were measured by the same assay. The minimal detectable dose of PYY is $10.0 \mathrm{pg} / \mathrm{ml}$. Intra- and inter-assay CV were 5.3 and $7.0 \%$ respectively.

Plasma CCK concentrations (pmol/l) were determined by a sensitive and specific RIA (24). In short, the antibody (CH40IX), raised in rabbits, was specifically directed to the biologically active site of CCK, including the sulfated tyrosyl residue at position 7 from the C-terminal end, and showed no cross-reactivity with unsulfated CCK-8, unsulfated gastrin-17 or unsulfated gastrin-34. The cross-reactivity to sulfated gastrin- 17 was $<1 \%$. The mean minimal detectable concentration in extracted plasma samples was $0.3 \pm 0.1 \mathrm{pmol} / \mathrm{l}$. The intra-assay CV was between $5.6 \%(0.7 \mathrm{pmol} / \mathrm{l})$ and $7.2 \%(15.1 \mathrm{pmol} / \mathrm{l})$. 


\section{Statistical analysis}

We used IBM SPSS Statistics (version 20.0, IBM Corp., Armonk, NY, USA) for data analysis. Results were expressed in mean and s.D. unless otherwise stated. Baseline levels were defined as mean of the value at time point $-15 \mathrm{~min}$ and the value at time point $0 \mathrm{~min}$. For comparison between the two groups, the independent two-sample $t$-tests were used; for comparison within a group, paired two-sample $t$-tests were used. Furthermore, data for leptin, ghrelin, PYY and CCK were compared by ANCOVA, using age and gender as cofactors. Moreover, leptin was corrected for percentage FM and compared using independent two-sample $t$-tests and ANCOVA. Comparison for dichotomized data was conducted using Fisher's exact test. Correlations between variables were calculated using the Pearson's correlation coefficient. Waist:hip ratio was calculated by dividing waist circumference by hip circumference. Diabetes was defined by patients either taking oral antidiabetics or according to the WHO criteria. Hypertension was defined by patients either taking medications for hypertension or having a blood pressure above $140 \mathrm{mmHg}$ systolic or above $90 \mathrm{mmHg}$ diastolic, calculating the mean out of three consecutive measurements during the visit. A $P$ value $<0.05$ was considered as the nominal level of significance.

\section{Results}

Fifty percent of CP patients $(n=20)$ were male and $50 \%$ female $(n=20)$, whereas $72.5 \%$ of NFPA patients $(n=29)$ were male and $27.5 \%(n=11)$ female. The gender distribution between both groups was not significantly different $(P=0.066)$. The mean age in the $\mathrm{CP}$ group was 49.6 years ( \pm 14.3 years), and in the NFPA group 63.4 years $( \pm 9.8$ years); this difference was highly significant $(P<0.001)$. BMI and body FM were significantly higher in CP than in NFPA patients (Table 1).

Slightly significantly more patients with CP had insufficiency of the somatotropic axis $(P<0.05)$, highly significantly more had diabetes insipidus $(P<0.001)$, whereas the prevalence of the other hormonal pituitary insufficiencies (thyreotropic, gonadotropic and corticotropic) did not differ significantly between groups (Table 1). At the time of diagnosis, $34 \mathrm{CP}$ patients had suprasellar, in two only intrasellar tumor growth and in four patients tumor growth was not known. Glucose levels at baseline were significantly higher for CP than for NFPA patients, but did not differ at $120 \mathrm{~min}$ after glucose intake. The prevalence of DM was not significantly different in patients with $\mathrm{CP}(n=7)$ compared with patients with NFPA $(n=4)$ (18 vs $10 \%, P=$ NS). Significantly more patients with NFPA had hypertension $(n=28$ (70\%) vs $n=16(40 \%)$, $P=0.013)$. For more patients' characteristics and variables see Table 1 .

Comparing CP patients with childhood onset with that of adult onset, differences in HbA1c could be found. Patients with childhood onset had lower HbA1c levels $(5.5 \%( \pm 0.50 \%))$ compared with adult onset patients $(6.0 \%( \pm 0.96 \%), P<0.05)$. No differences were seen in pituitary insufficiencies, GH substitution, number of operations, number of radiations, glucose levels, insulin levels, leptin, ghrelin, CCK, PYY, BMI, waist:hip ratio and FM.

Insulin levels at baseline and after glucose load did not differ between CP and NFPA patients. Leptin levels at baseline and $60 \mathrm{~min}$ after glucose intake were significantly higher in patients with CP compared with patients with NFPA. When adjusted for gender and age, the difference in leptin levels did not persist. Leptin levels decreased significantly after $60 \mathrm{~min}$ in patients with $\mathrm{CP}(P=0.019)$, whereas in patients with NFPA leptin levels tended to decrease without reaching statistical significance $(P=0.089)$. The percentage decline was not significantly different between CP and NFPA patients (Table 2). Leptin levels corrected for percentage FM at baseline and after $60 \mathrm{~min}$ were significantly higher in patients with CP compared with patients with NFPA (baseline: $\mathrm{CP}, 0.66 \mu \mathrm{g} / \mathrm{l} \%( \pm 0.67 \mu \mathrm{g} / 1 \%)$ and NFPA, $0.32 \mu \mathrm{g} / 1 \%$ $( \pm 0.25 \mu \mathrm{g} / \mathrm{l} \%), \quad P=0.005$ and after $60 \mathrm{~min}: \mathrm{CP}$, $0.60 \mu \mathrm{g} / 1 \% \quad( \pm 0.60 \mu \mathrm{g} / 1 \%) \quad$ and $\quad \mathrm{NFPA}, \quad 0.30 \mu \mathrm{g} / 1 \%$ $( \pm 0.25 \mu \mathrm{g} / \mathrm{l} \%), P=0.008)$. When adjusted for gender and age, the differences in percentage FM corrected for leptin did not persist.

Ghrelin levels at baseline and after $60 \mathrm{~min}$ were significantly lower in CP compared with NFPA patients. Correcting for age and gender eliminated the difference at baseline, whereas ghrelin levels at $60 \mathrm{~min}$ remained significantly lower for CP. In both groups, ghrelin levels decreased significantly after glucose load (both $P<0.001$ ). The percentage decline was significantly lower for CP. PYY and CCK at baseline, as well as after $60 \mathrm{~min}$ did not differ significantly between the two groups. PYY (CP, $P=0.039$ and NFPA, $P=0.002$ ) and CCK (for both $P=0.001$ ) significantly increased after glucose load in both groups. The percentage increase for CP and NFPA did not differ significantly between groups for PYY and CCK (Table 2).

Despite the well-known correlations for leptin and insulin with FM and BMI, we were able to detect the following significant correlations: in the $\mathrm{CP}$ group, 
Table 2 Insulin, leptin, ghrelin, PYY and CCK values for patients with CP and NFPA. Data are shown in mean \pm s.D. Comparisons were calculated using independent two samples $t$-test and ANCOVA corrected for age and gender.

\begin{tabular}{|c|c|c|c|c|}
\hline & CP $(n=40)$ & NFPA $(n=40)$ & t-test & $\begin{array}{c}\text { ANCOVA } \\
\text { adjusted } \\
\text { for age/gender }\end{array}$ \\
\hline \multicolumn{5}{|l|}{ Insulin $(\mu \mathrm{E} / \mathrm{ml})$} \\
\hline $0 \mathrm{~min}$ & $22 \pm 15$ & $19 \pm 12$ & NS & NS \\
\hline $120 \mathrm{~min}$ & $106 \pm 87$ & $114 \pm 75$ & NS & NS \\
\hline \multicolumn{5}{|l|}{ Leptin $(\mu \mathrm{g} / \mathrm{l})$} \\
\hline $0 \mathrm{~min}$ & $27.9 \pm 34.2$ & $11.9 \pm 11.6$ & $P=0.008$ & NS $(P=0.395)$ \\
\hline $60 \mathrm{~min}$ & $25.3 \pm 29.8$ & $11.2 \pm 12.1$ & $P=0.008$ & NS $(P=0.402)$ \\
\hline Decrease $(\%)$ & $7.2 \pm 13.7$ & $9.8 \pm 13.3$ & NS & NS \\
\hline \multicolumn{5}{|c|}{ Leptin/fat mass $(\mu \mathrm{g} / \mathrm{l} \%)$} \\
\hline $0 \mathrm{~min}$ & $0.66 \pm 0.67$ & $0.32 \pm 0.25$ & $P=0.005$ & NS $(P=0.341)$ \\
\hline $60 \mathrm{~min}$ & $0.60 \pm 0.60$ & $0.30 \pm 0.25$ & $P=0.008$ & NS $(P=0.333)$ \\
\hline \multicolumn{5}{|l|}{ Ghrelin (ng/l) } \\
\hline $0 \mathrm{~min}$ & $131 \pm 129$ & $191 \pm 119$ & $P=0.035$ & NS $(P=0.067)$ \\
\hline $60 \mathrm{~min}$ & $95 \pm 73$ & $134 \pm 72$ & $P=0.018$ & $P=0.039$ \\
\hline Decrease (\%) & $18 \pm 16$ & $26 \pm 12$ & $P=0.011$ & $P=0.035$ \\
\hline \multicolumn{5}{|l|}{ PYY (ng/l) } \\
\hline $0 \min$ & $208 \pm 106$ & $178 \pm 74$ & NS & NS \\
\hline $60 \mathrm{~min}$ & $240 \pm 132$ & $203 \pm 65$ & NS & NS \\
\hline Increase $(\%)$ & $15 \pm 34$ & $18 \pm 24$ & NS & NS \\
\hline \multicolumn{5}{|l|}{ CCK (pmol/l) } \\
\hline $0 \mathrm{~min}$ & $0.8 \pm 0.7$ & $1.2 \pm 1.0$ & NS & NS \\
\hline $60 \mathrm{~min}$ & $2.5 \pm 0.9$ & $2.7 \pm 0.7$ & NS & NS \\
\hline Increase $(\%)$ & $428 \pm 514$ & $311 \pm 453$ & NS & NS \\
\hline
\end{tabular}

$n$, number of patients; NS, not significant; decrease (\%), percentage decrease from baseline to 60 min; increase (\%), percentage increase from baseline to $60 \mathrm{~min}$.

a significant correlation for age and baseline glucose $(r=$ $0.438, P<0.01$ ) and in the NFPA group, a significant correlation for PYY and baseline insulin $(r=0.586$, $P<0.001)$ and for BMI and basal glucose $(r=0.445$, $P<0.01)$. No further correlations were found, especially not for the gut hormones.

\section{Discussion}

The main results of our study were that: i) leptin levels were significantly higher at baseline and after glucose intake and decreased significantly in our patients with $\mathrm{CP}$ compared with our patients with NFPA; ii) baseline and post-meal ghrelin levels were significantly lower and decrease after glucose load was significantly smaller in our patients with CP than in our patients with NFPA; and iii) insulin levels, PYY and CCK did not differ significantly in fasting condition and the secretion after glucose intake was not different between our two groups. The differences in leptin and ghrelin levels at baseline and the post-meal differences for leptin did not persist when correcting by age and gender.
BMI, FM and fasting glucose levels were significantly higher in our CP patients, despite the younger age of this patient group. Thus, our patients with CP have more metabolic complications and higher FM than our patients with NFPA. The reason for more patients with NFPA having hypertension can be explained by the higher mean age of this patient group.

It might be argued that one influencing factor of these findings could be the prevalence of pituitary insufficiencies. Particularly, GH deficiency is a risk factor for developing a metabolic syndrome (25). Slightly more patients with CP had GH deficiency. But the amount of patients with $\mathrm{GH}$ deficiency having no GH replacement did not differ between the two groups (CP, $n=15$ and NFPA, $n=16$ ) and the IGF1 levels were not significantly different between groups. The prevalence of other insufficiencies of the anterior pituitary was not significantly different between the two groups and all patients were on permanent, adequate hormone substitution. Hence, we do not think that pituitary insufficiencies did have a significant influence on the metabolic differences observed between our CP and NFPA patients. 
It is not clear whether the changes in leptin and ghrelin levels at baseline and after glucose load are the reason for or the consequence of higher FM and BMI. Interestingly, the baseline differences in leptin and ghrelin levels and the post-meal leptin levels did not persist when correcting by age and gender. The fact that patients with CP were younger than patients with NFPA would rather strengthen the noticeable results of higher leptin levels in $\mathrm{CP}$, as FM is known to increase with age, and leptin positively correlates with FM (10). It can be speculated that the tendency - even if not significant - of more female patients in the CP group might lead to the loss of significant differences in leptin levels after correcting for age and gender. Females are described to have more FM and thus higher leptin levels $(26,27)$. Furthermore, female hypopituitary patients have a higher risk of vascular disease than females with a normal function of the same age, which could also bias the results (28). The change in the baseline result for ghrelin levels after correcting for age and gender could also be explained by the younger age and the higher number of women in the CP group, as ghrelin levels are higher in women and young people (29). Changes in leptin and ghrelin should be evaluated in comparison with an obese healthy control group to further clarify whether they are due to the disease or the obesity.

Increased leptin levels in $\mathrm{CP}$ patients have been reported before $(11,30)$. Two causes could account for this: on the one hand, the higher FM of CP patients and on the other hand, a leptin resistance caused by the damage of the hypothalamus (31).

In our CP patients, leptin levels decreased after glucose intake. A tendency toward a decrease was also seen in patients with NFPA, but without reaching statistical significance. We reported before that leptin levels decrease during OGTT in patients with pituitary disease, though not in healthy controls $(21,22,32)$. We hypothesized that this phenomenon is due to a central dysregulation caused by the damage of the pituitary region. As we first saw this phenomenon in patients with acromegaly, we speculated that it could be due to non-physiological high GH levels during active disease (22). This is underlined by the fact that some of the GH cells in the pituitary contain leptin granules and have leptin receptors (33). But the exact nature of the hypothesized central dysregulation is not known. Apart from that, a leptin decline during OGTT has been described after carbohydrate restriction and following a high-fat meal in obese men $(34,35)$ and healthy men (36). The reason why leptin levels decrease in response to glucose is not known. Jenkins et al. (35) speculated the fall in serum leptin in association with reduced carbohydrate intake before substantial loss of body fat, which suggests a role for leptin in defending the body's carbohydrate stores and implicates leptin in the satiating effects of carbohydrate. Imbeault et al. (34) hypothesized that obesity is related to an impaired regulation of leptin by insulin, because leptin levels increased in lean men but decreased in obese men following a high-fat meal. Poppitt et al. reported a decrease in leptin levels after high-fat meals in healthy men. They mentioned that a decrease in circulating leptin over $24 \mathrm{~h}$ may represent an adverse risk for obesity, but this remains controversial and recombinant leptin weight loss therapy in hyperleptinemic obese subjects has been met with limited success (36). In some normal subjects, leptin levels have been reported to not change after food intake and in some obese women an increase in leptin levels has been seen (26). In CP patients, the tumor often lies in the suprasellar region invading hypothalamic structures, whereas in patients with NFPA suprasellar tumor parts rarely damage the hypothalamus. Considering this, we can speculate that the observed, more pronounced reduction in leptin levels after glucose load in patients with $\mathrm{CP}$ is a consequence of the hypothalamic damage rather than the involvement of the pituitary. Still, we cannot rule out that this finding is only due to a statistical calculation. The range of leptin values was wide in our patients and the reduction of leptin after glucose was low so that this finding could only be statistically calculated without causality.

Our data showed reduced baseline and post-glucose ghrelin levels in patients with CP. The reduced ghrelin levels can be explained by the positive energy balance shown by the high-FM and BMI in patients with $\mathrm{CP}$, as ghrelin levels are well known to be lower in obese and higher in lean subjects (37). The ghrelin decrease after glucose load was significantly lower in patients with $\mathrm{CP}$ (18\%) than in patients with NFPA (26\%). However, both declines were lower compared with healthy control subjects (28 and $34 \%$ respectively) $(13,38)$ and similar to acromegalic patients (19 and 26\% respectively) $(22,39)$. Accordingly, Roth et al. (15) reported reduced ghrelin levels and a reduced ghrelin response after meals in patients with $\mathrm{CP}$ compared with obese controls, and Goldstone et al. (18) described lower fasting and postprandial ghrelin levels in obese patients with $\mathrm{CP}$ than in normal controls. Previously, it has been postulated that ghrelin levels might be high in patients with $\mathrm{CP}$, as hyperghrelinemia was found in Prader-Willi syndrome (18), a genetic cause of hypothalamic obesity. But in the 
mentioned study, ghrelin levels were low in patients with CP compared with patients with Prader-Willi syndrome. However, similar ghrelin secretion compared with obese controls has also been reported $(18,19)$. It seems as if reduced ghrelin response after meals is due to obesity itself as it has been seen in obese patients with other diseases, too $(18,40)$.

Our patients with CP had equal levels of baseline and post-glucose insulin compared with patients with NFPA. The reason for that finding is not clear. We had expected patients with $\mathrm{CP}$ to have higher insulin levels either as a consequence of an increased vagal tone caused by lesions of the ventromedial nuclei (9) or as an effect of obesity itself. One reason of similar insulin levels might be the younger age of patients with $\mathrm{CP}$, as women above 50 years have been shown to present higher HOMA-IR levels than younger women (41). Previously, it has been described that CP patients have high insulin levels $(42,43)$. Conflictive results have been reported regarding insulin levels in patients with CP compared with other obese subjects: Roth et al. (15) did show higher insulin levels in patients with $\mathrm{CP}$ than in obese controls and Simoneau-Roy et al. (44) also reported increased insulin secretion compared with BMI-matched controls, whereas Shaikh et al. (30) described similar insulin levels in patients with CP compared with other obese patients and controls.

Fasting levels of PYY and CCK were not significantly different between our two patient groups, nor did the secretion pattern of PYY and CCK after glucose intake differ. One study has reported that the response of PYY after meals was weaker in patients with CP compared with normal controls (15), but another study did not reveal any differences in secretion pattern of PYY (18). As far as we know, dynamics of CCK after food intake have not yet been studied in patients with CP. It was assumed that an intact vagal-brainstem-hypothalamic pathway is required for gut hormones to influence food intake (15). Hence, we suggested that in $\mathrm{CP}$ patients with a damaged hypothalamic region PYY and CCK secretion would be impaired. However, it might be concluded from our data that PYY and CCK do not seem to have any influence on the development of obesity in our patients with CP.

The study has some limitations. In particular, the heterogeneous study population and many cofounders, such as different age at diagnosis, different amount of pituitary insufficiencies, and metabolic differences could possibly affect hormonal profile, independent of disease status. Treatment differences in the extent of surgery are possible and cannot be ruled out due to the number of different surgical centers. Moreover, due to the cross-sectional design the causality of our results cannot be proven and the descriptive nature of this study might limit the conclusions. Furthermore, we did not assess acylated and desacylated ghrelin levels but only total ghrelin levels.

In summary, we could show in a large cohort of patients with CP that they have more signs of the metabolic syndrome like obesity, higher FM, and higher glucose levels compared with patients with NFPA, although they are younger. Moreover, our results point into the direction that patients with $\mathrm{CP}$ have disturbances of food regulation hormones in terms of higher leptin levels and lower ghrelin levels as well as a significant leptin decline and a reduced ghrelin response after glucose intake compared with our patients with NFPA. But the differences in baseline leptin, post-glucose leptin and baseline ghrelin levels did not persist when adjusting for age and gender. Levels of PYY and CCK were not altered in our patients with CP. Thus, they do not seem to be responsible for the metabolic changes in these patients. We want to point out that the results were found in our patient groups and therefore may not be universally valid for all patients with $\mathrm{CP}$ and NFPA.

\section{Declaration of interest}

The authors declare that there is no conflict of interest that could be perceived as prejudicing the impartiality of the research reported.

\section{Funding}

The underlying clinical trial was partly sponsored by Ipsen Pharma, Ettlingen, Germany by an independent grant. Ipsen Pharma was not involved in designing the protocol or in data analysis.

\section{Acknowledgements}

The authors thank Dr Maja Hoegg-Beiler for the critical language revisions and Rita Schwaiger, Minerva Petrovitsch and Nicole Lichter for helping with the laboratory analysis.

\section{References}

1 Muller HL, Gebhardt U, Wessel V, Schroder S, Kolb R, Sorensen N, Maroske J \& Hanisch E. First experiences with laparoscopic adjustable gastric banding (LAGB) in the treatment of patients with childhood craniopharyngioma and morbid obesity. Klinische Pädiatrie 2007219 323-325. (doi:10.1055/s-2007-985848)

2 Vinchon M, Weill J, Delestret I \& Dhellemmes P. Craniopharyngioma and hypothalamic obesity in children. Child's Nervous System 200925 347-352. (doi:10.1007/s00381-008-0754-x)

3 Fournier A, Pauli A, Cecile JP, Cousin J \& Decherf A. Craniopharyngioma having the appearance of an isolated obesity. Journal des Sciences Médicales de Lille 196886 171-175. 


tra

4 Crom DB, Smith D, Xiong Z, Onar A, Hudson MM, Merchant TE \& Morris EB. Health status in long-term survivors of pediatric craniopharyngiomas. Journal of Neuroscience Nursing 201042 323-328 (quiz 329-330). (doi:10.1097/JNN.0b013e3181f8a59d)

5 Lee M \& Korner J. Review of physiology, clinical manifestations, and management of hypothalamic obesity in humans. Pituitary 200912 87-95. (doi:10.1007/s11102-008-0096-4)

6 Morton GJ, Cummings DE, Baskin DG, Barsh GS \& Schwartz MW. Central nervous system control of food intake and body weight. Nature 2006443 289-295. (doi:10.1038/nature05026)

7 Wynne K, Stanley S, McGowan B \& Bloom S. Appetite control. Journal of Endocrinology 2005184 291-318. (doi:10.1677/joe.1.05866)

8 Roth CL. Hypothalamic obesity in patients with craniopharyngioma: profound changes of several weight regulatory circuits. Frontiers in Endocrinology 20112 49. (doi:10.3389/fendo.2011.00049)

9 Lustig RH, Post SR, Srivannaboon K, Rose SR, Danish RK, Burghen GA, Xiong X, Wu S \& Merchant TE. Risk factors for the development of obesity in children surviving brain tumors. Journal of Clinical Endocrinology and Metabolism 200388 611-616. (doi:10.1210/jc.2002021180)

10 Hamann A \& Matthaei S. Regulation of energy balance by leptin. Experimental and Clinical Endocrinology \& Diabetes 1996104 293-300. (doi:10.1055/s-0029-1211457)

11 Roth C, Wilken B, Hanefeld F, Schroter W \& Leonhardt U. Hyperphagia in children with craniopharyngioma is associated with hyperleptinaemia and a failure in the downregulation of appetite. European Journal of Endocrinology 1998138 89-91. (doi:10.1530/eje.0.1380089)

12 Date Y, Kojima M, Hosoda H, Sawaguchi A, Mondal MS, Suganuma T, Matsukura S, Kangawa K \& Nakazato M. Ghrelin, a novel growth hormone-releasing acylated peptide, is synthesized in a distinct endocrine cell type in the gastrointestinal tracts of rats and humans. Endocrinology 2000141 4255-4261.

13 Shiiya T, Nakazato M, Mizuta M, Date Y, Mondal MS, Tanaka M, Nozoe S, Hosoda H, Kangawa K \& Matsukura S. Plasma ghrelin levels in lean and obese humans and the effect of glucose on ghrelin secretion. Journal of Clinical Endocrinology and Metabolism 200287 240-244. (doi:10.1210/jcem.87.1.8129)

14 Kanumakala S, Greaves R, Pedreira CC, Donath S, Warne GL, Zacharin MR \& Harris M. Fasting ghrelin levels are not elevated in children with hypothalamic obesity. Journal of Clinical Endocrinology and Metabolism 200590 2691-2695. (doi:10.1210/jc.2004-2175)

15 Roth CL, Gebhardt U \& Muller HL. Appetite-regulating hormone changes in patients with craniopharyngioma. Obesity 201119 36-42. (doi:10.1038/oby.2010.80)

16 Lin S, Boey D \& Herzog H. NPY and Y receptors: lessons from transgenic and knockout models. Neuropeptides 200438 189-200. (doi:10.1016/ j.npep.2004.05.005)

17 Batterham RL, Heffron H, Kapoor S, Chivers JE, Chandarana K, Herzog H, Le Roux CW, Thomas EL, Bell JD \& Withers DJ. Critical role for peptide YY in protein-mediated satiation and body-weight regulation. Cell Metabolism 20064 223-233. (doi:10.1016/j.cmet.2006. 08.001)

18 Goldstone AP, Patterson M, Kalingag N, Ghatei MA, Brynes AE, Bloom SR, Grossman AB \& Korbonits M. Fasting and postprandial hyperghrelinemia in Prader-Willi syndrome is partially explained by hypoinsulinemia, and is not due to peptide YY3-36 deficiency or seen in hypothalamic obesity due to craniopharyngioma. Journal of Clinical Endocrinology and Metabolism 200590 2681-2690. (doi:10.1210/ jc.2003-032209)

19 Daousi C, MacFarlane IA, English PJ, Wilding JP, Patterson M, Dovey TM, Halford JC, Ghatei MA \& Pinkney JH. Is there a role for ghrelin and peptide-YY in the pathogenesis of obesity in adults with acquired structural hypothalamic damage? Journal of Clinical Endocrinology and Metabolism 200590 5025-5030. (doi:10.1210/ jc.2004-1874)
20 Woods SC. Gastrointestinal satiety signals I. An overview of gastrointestinal signals that influence food intake. American Journal of Physiology. Gastrointestinal and Liver Physiology 2004286 G7-G13. (doi:10.1152/ajpgi.00448.2003)

21 Roemmler J, Kuenkler M, Otto B, Arafat AM, Bidlingmaier M \& Schopohl J. Influence of long-term growth hormone replacement on leptin and ghrelin in GH deficiency before and after glucose load. Regulatory Peptides 2009158 40-46. (doi:10.1016/j.regpep.2009.07.001)

22 Roemmler J, Otto B, Steffin B, Bidlingmaier M \& Schopohl J. Serum leptin and ghrelin levels in active and inactive acromegalic patients during an oral glucose tolerance test. Experimental and Clinical Endocrinology \& Diabetes 2009117 135-141. (doi:10.1055/s-20081078739)

23 Wu Z, Bidlingmaier M, Liu C, De Souza EB, Tschop M, Morrison KM \& Strasburger CJ. Quantification of the soluble leptin receptor in human blood by ligand-mediated immunofunctional assay. Journal of Clinical Endocrinology and Metabolism 200287 2931-2939. (doi:10.1210/jcem. 87.6.8610)

24 Riepl RL, Fiedler F, Ernstberger M, Teufel J \& Lehnert P. Effect of intraduodenal taurodeoxycholate and L-phenylalanine on pancreatic secretion and on gastroenteropancreatic peptide release in man. European Journal of Medical Research 19961 499-505.

25 Doga M, Bonadonna S, Gola M, Mazziotti G \& Giustina A. Growth hormone deficiency in the adult. Pituitary 20069 305-311. (doi:10.1007/s11102-006-0410-y)

26 Bougoulia M, Tzotzas T, Efthymiou H, Koliakos G, Konstantinidis T, Triantos A \& Krassas GE. Leptin concentrations during oral glucose tolerance test (OGTT) in obese and normal weight women. International Journal of Obesity and Related Metabolic Disorders 199923 625-628. (doi:10.1038/sj.ijo.0800891)

27 Saad MF, Damani S, Gingerich RL, Riad-Gabriel MG, Khan A, Boyadjian R, Jinagouda SD, el-Tawil K, Rude RK \& Kamdar V. Sexual dimorphism in plasma leptin concentration. Journal of Clinical Endocrinology and Metabolism 199782 579-584.

28 Bulow B, Hagmar L, Eskilsson J \& Erfurth EM. Hypopituitary females have a high incidence of cardiovascular morbidity and an increased prevalence of cardiovascular risk factors. Journal of Clinical Endocrinology and Metabolism 200085 574-584.

29 Makovey J, Naganathan V, Seibel M \& Sambrook P. Gender differences in plasma ghrelin and its relations to body composition and bone - an opposite-sex twin study. Clinical Endocrinology 200766 530-537.

30 Shaikh MG, Grundy RG \& Kirk JM. Hyperleptinaemia rather than fasting hyperinsulinaemia is associated with obesity following hypothalamic damage in children. European Journal of Endocrinology 2008159 791-797. (doi:10.1530/EJE-08-0533)

31 Guran T, Turan S, Bereket A, Akcay T, Unluguzel G, Bas F, Gunoz H, Saka N, Bundak R, Darendeliler F et al. The role of leptin, soluble leptin receptor, resistin, and insulin secretory dynamics in the pathogenesis of hypothalamic obesity in children. European Journal of Pediatrics 2009 168 1043-1048. (doi:10.1007/s00431-008-0876-x)

32 Roemmler J, Otto B, Arafat AM, Bidlingmaier M \& Schopohl J. Influence of pegvisomant on serum ghrelin and leptin levels in acromegalic patients. European Journal of Endocrinology 2010163 727-734. (doi:10.1530/EJE-10-0344)

33 Lloyd RV, Jin L, Tsumanuma I, Vidal S, Kovacs K, Horvath E, Scheithauer BW, Couce ME \& Burguera B. Leptin and leptin receptor in anterior pituitary function. Pituitary 20014 33-47.

34 Imbeault P, Doucet E, Mauriege P, St-Pierre S, Couillard C, Almeras N, Despres JP \& Tremblay A. Difference in leptin response to a high-fat meal between lean and obese men. Clinical Science 2001101 359-365. (doi:10.1042/CS20010024)

35 Jenkins AB, Markovic TP, Fleury A \& Campbell LV. Carbohydrate intake and short-term regulation of leptin in humans. Diabetologia $1997 \mathbf{4 0}$ 348-351.

36 Poppitt SD, Leahy FE, Keogh GF, Wang Y, Mulvey TB, Stojkovic M, Chan YK, Choong YS, McArdle BH \& Cooper GJ. Effect of high-fat meals 
and fatty acid saturation on postprandial levels of the hormones ghrelin and leptin in healthy men. European Journal of Clinical Nutrition 200660 77-84. (doi:10.1038/sj.ejcn.1602270)

37 Tschop M, Weyer C, Tataranni PA, Devanarayan V, Ravussin E \& Heiman ML. Circulating ghrelin levels are decreased in human obesity. Diabetes 200150 707-709. (doi:10.2337/diabetes.50.4.707)

38 Caixas A, Bashore C, Nash W, Pi-Sunyer F \& Laferrere B. Insulin, unlike food intake, does not suppress ghrelin in human subjects. Journal of Clinical Endocrinology and Metabolism 200287 1902. (doi:10.1210/jcem. 87.4.8538)

39 Freda PU, Reyes CM, Conwell IM, Sundeen RE \& Wardlaw SL. Serum ghrelin levels in acromegaly: effects of surgical and long-acting octreotide therapy. Journal of Clinical Endocrinology and Metabolism 2003 88 2037-2044.

40 Haqq AM, Farooqi IS, O'Rahilly S, Stadler DD, Rosenfeld RG, Pratt KL, LaFranchi SH \& Purnell JQ. Serum ghrelin levels are inversely correlated with body mass index, age, and insulin concentrations in normal children and are markedly increased in Prader-Willi syndrome. Journal of Clinical Endocrinology and Metabolism 200388 174-178. (doi:10.1210/jc.2002-021052)
41 Gayoso-Diz P, Otero-Gonzalez A, Rodriguez-Alvarez MX, Gude F, Cadarso-Suarez C, Garcia F \& De Francisco A. Insulin resistance index (HOMA-IR) levels in a general adult population: curves percentile by gender and age. The EPIRCE study. Diabetes Research and Clinical Practice 201194 146-155. (doi:10.1016/j.diabres.2011. 07.015)

42 Lustig RH, Rose SR, Burghen GA, Velasquez-Mieyer P, Broome DC, Smith K, Li H, Hudson MM, Heideman RL \& Kun LE. Hypothalamic obesity caused by cranial insult in children: altered glucose and insulin dynamics and reversal by a somatostatin agonist. Journal of Pediatrics 1999135 162-168. (doi:10.1016/S0022-3476(99)70017-X)

43 Pinto G, Bussieres L, Recasens C, Souberbielle JC, Zerah M \& Brauner R. Hormonal factors influencing weight and growth pattern in craniopharyngioma. Hormone Research 200053 163-169. (doi:10.1159/ 000023562)

44 Simoneau-Roy J, O'Gorman C, Pencharz P, Adeli K, Daneman D \& Hamilton J. Insulin sensitivity and secretion in children and adolescents with hypothalamic obesity following treatment for craniopharyngioma. Clinical Endocrinology 201072 364-370. (doi:10.1111/j.1365-2265.2009.03639.x)

Received 11 October 2013

Revised version received 29 December 2013

Accepted 28 January 2014 